Journal of Computer Science 6 (11): 1272-1275, 2010

ISSN 1549-3636

(C) 2010 Science Publications

\title{
Kinematic Analysis of Exoskeleton Suit for Human Arm
}

\author{
Surachai Panich \\ Srinakharinwirot University, 114 Sukhumvit 23, Bangkok 10110
}

\begin{abstract}
Problem statement: There are many robotic arms developed for providing care to physically disabled people. It is difficult to find robot designs in literature that articulate such a procedure. Therefore, it is our hope that the design work shown in this study may serve as a good example of a systematic method for rehabilitation robot design. Approach: The arm exoskeleton suit was developed to increase human's strength, endurance, or speed enabling them to perform tasks that they previously could not perform. It should not impede the user's natural motion and should be comfortable and safe to wear and easy to use. Although movement is difficult for them, they usually want to go somewhere by themselves. Results: The kinematic exoskeleton suit for human arms is simulated by MATLAB software. The exoskeleton suit of human arm consists of one link length, three link twists, two link offsets and three joint angles. Conclusion: This study introduced the kinematic of exoskeleton suit for human arm. The exoskeleton suit can be used to be instrument for anyone who needs to improve human's performance. It will increase the strength of human that can lift heavy load or help handicapped patients, who cannot use their arm.
\end{abstract}

Key words: Exoskeleton suit, kinematic, human arm

\section{INTRODUCTION}

Exoskeleton systems for human operators offer a wide range of possible applications. For patients they can offer assistance during their rehabilitation process by guiding motions on correct trajectories to help relearning motion patterns, or give force support to be able to perform certain motions. In factory environments, they could remove load from workers to avoid wearing down their bodies through strenuous physical work. In the military arena, soldiers in the field will benefit if they have greater load carrying mobility with less strain and ability to walk further distances than present conditions allow. An exoskeleton is an external structural mechanism whose joints correspond to those of the human body. It is worn by the human and the physical contact between the operator and the exoskeleton allows direct transfer of mechanical power and information signals (Nandhakumar et al., 2009). One of the human limits in performing physical tasks is the muscle's strength. In addition, muscle strength may be decreased substantially as a result of verity of neuromuscular diseases, muscular atrophy and dystrophy in disabled people. Integrating humans and robotic machines into one system offers multiple opportunities for creating new assistive technologies that can be used in biomedical, industrial and aerospace applications. As opposed to strength limitation, humans possess naturally developed algorithms with complex and highly specialized control methods, using higher and lower neural centers that enable them to perform very complicated tasks such as locomotion while avoiding object collision. The mechanical power of the machine integrated with the inherent human control system could perform tasks that need high forces in a very efficient manner. This is the underlying principle in the design of exoskeleton systems. There are many researches about this instrument. One of these systems is HAL Project, which provides torques for the user's hip and knee joints according to the user's intention by using EMG signal as the primary command signal. The HAL project can help disabled or elder people smoothly perform everyday activities such as walking, climbing up and down stairs. Moreover, it can aid a normal people to carry heavy load.

\section{MATERIALS AND METHODS}

The human arm and its capability make the human arm race class apart from other animals. The design of human arm structure is a unique marvel and is still a challenge to replicate. The human arm's basic performance specifications are defined from the zero reference position, which is the stretched arm and hand straight out and horizontal with the palm in downward direction (Berns et al., 1998). From the human arm mechanism as shown in Fig. 1, particularly the human arm's joints are the one of the most complex part of human body. 


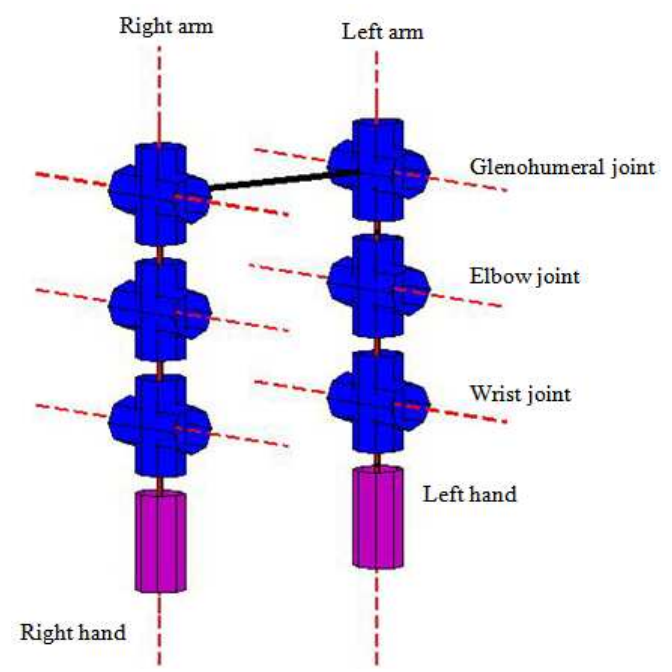

Fig. 1: Link kinematic of exoskeleton suit for human arm

Table 1: The kinematic of links and joints typical robots are serial link manipulators comprising

\begin{tabular}{|c|c|c|}
\hline Type & Parameter & Description \\
\hline Link length & $\mathrm{a}_{\mathrm{i}}$ & $\begin{array}{l}\text { Offset distance between the } \mathrm{z}_{\mathrm{i}-1} \text { and } \mathrm{z}_{\mathrm{i}} \text { axes } \\
\text { along the } \mathrm{x}_{\mathrm{i}} \text { axis }\end{array}$ \\
\hline Link twist & $\alpha_{\mathrm{i}}$ & $\begin{array}{l}\text { Angle from the } \mathrm{z}_{\mathrm{i}-1} \text { axis to the } \mathrm{z}_{\mathrm{i}} \text { axis about } \\
\text { the } \mathrm{x}_{\mathrm{i}} \text { axis }\end{array}$ \\
\hline Link off set & $\mathrm{d}_{\mathrm{i}}$ & $\begin{array}{l}\text { Distance from the origin of frame } \mathrm{i}-1 \text { to } \\
\text { the } \mathrm{x}_{\mathrm{i}} \text { axis along the } \mathrm{z}_{\mathrm{i}-1} \text { axis }\end{array}$ \\
\hline Joint angle & $\theta_{\mathrm{i}}$ & $\begin{array}{l}\text { Angle between the } \mathrm{x}_{\mathrm{i}-1} \text { and } \mathrm{x}_{\mathrm{i}} \text { axes about } \\
\text { the } \mathrm{z}_{\mathrm{i}-1} \text { axis }\end{array}$ \\
\hline
\end{tabular}

Link kinematic of exoskeleton suit for human arm: The study of motion without regard to the forces which cause it. Within kinematics one studies the position, velocity and acceleration and all higher order derivatives of the position variables (Asfour and Dillmann, 2003; Sen et al., 2007).

The kinematic of links and joints (McKerrow, 1991) involves the study of the geometric and time based properties of the motion and in particular how the various links move with respect to one another and with time as detailed in Table 1. Typical robots are serial link manipulators comprising a set of bodies, called links, in a chain, connected by joints. Each joint has one degree of freedom, either translational or rotational. Joints and links may be described by parameters below.

\section{RESULTS}

The kinematic exoskeleton suit for human arm is simulated by MATLAB software (Mittal and Nagrath, 2003).

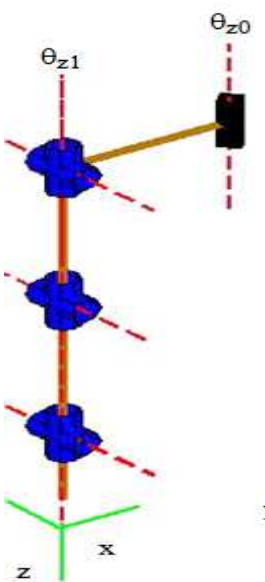

(a)

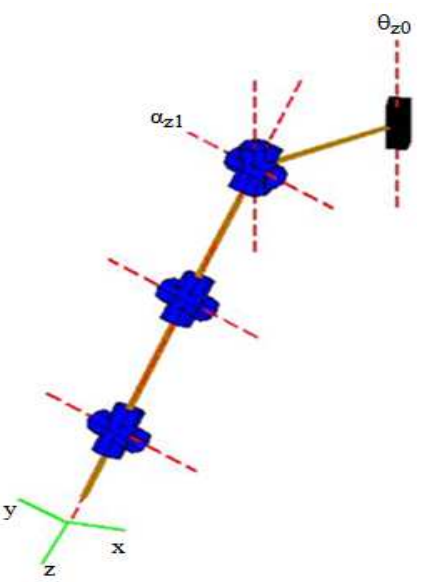

(b)
Fig. 2: Link kinematic of right arm in position 1

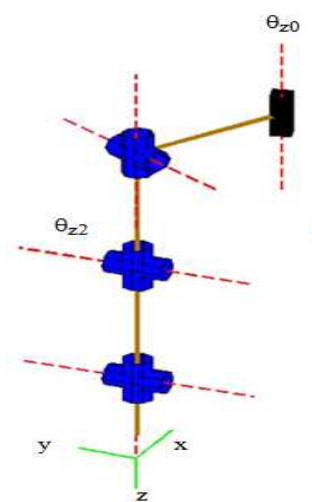

(a)

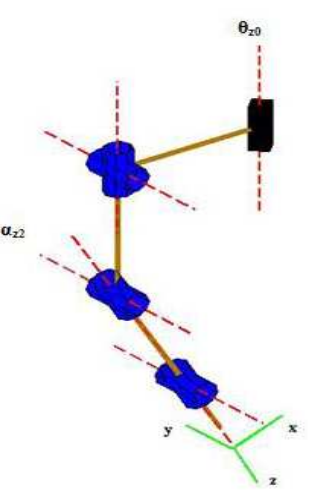

(b)
Fig. 3: Link kinematic of right arm in position 2

In Fig. 2a it shows exoskeleton suit for right arm with joint angle $\theta_{\mathrm{z} 1}$ and with link twist $\alpha_{\mathrm{z} 1}$ in Fig. $2 \mathrm{~b}$. The angle $\theta_{z 0}$ is attached with human body.

In Fig. 3a it shows the kinematic of position 2 about $\mathrm{Z}$ axis with joint angle $\theta_{\mathrm{z} 2}$ and link twist $\alpha_{\mathrm{z} 2}$ in Fig. 3b.

In Fig. 4a it shows the kinematic of position 3 about $\mathrm{Z}$ axis with joint angle $\theta_{\mathrm{z} 3}$ and link twist $\alpha_{\mathrm{z} 3}$ in Fig. $4 b$.

In Fig. 5a it shows the kinematic of position 4 about $\mathrm{Z}$ axis with joint angle $\theta_{\mathrm{z} 4}$ and link twist $\alpha_{\mathrm{z} 4}$ in Fig. 5b.

In Fig. 6a it shows the kinematic of position 5 about $\mathrm{Z}$ axis with joint angle $\theta_{\mathrm{z} 5}$ and link twist $\alpha_{\mathrm{z} 5}$ in Fig. 6 .

In Fig. 7a it shows the kinematic of position 6 about $\mathrm{Z}$ axis with joint angle $\theta_{\mathrm{z} 6}$ and link twist $\alpha_{z 6}$ in Fig. $7 b$. 


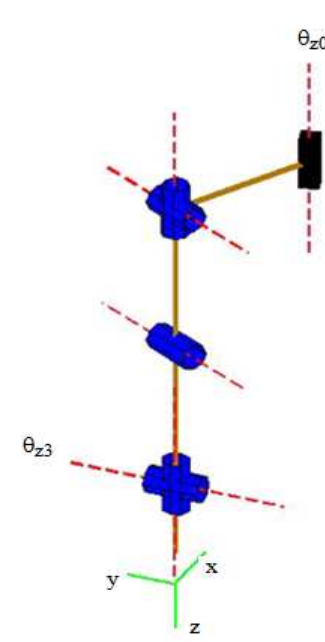

(a)

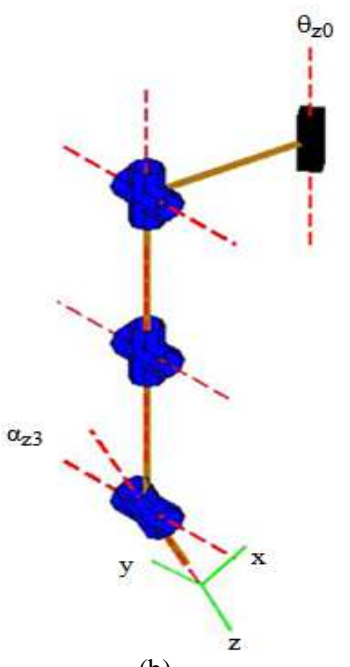

(b)

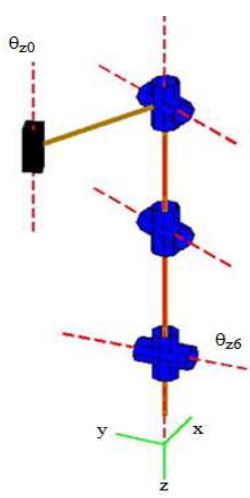

(a)

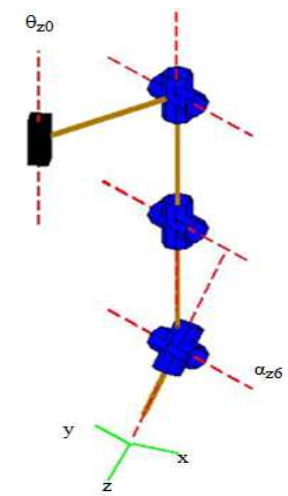

(b)
Fig. 7: Link kinematic of left arm in position 6

\section{DISCUSSION}

Fig. 4: Link kinematic of right arm in position 3

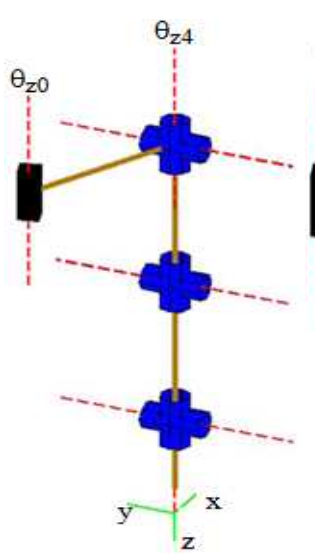

(a)

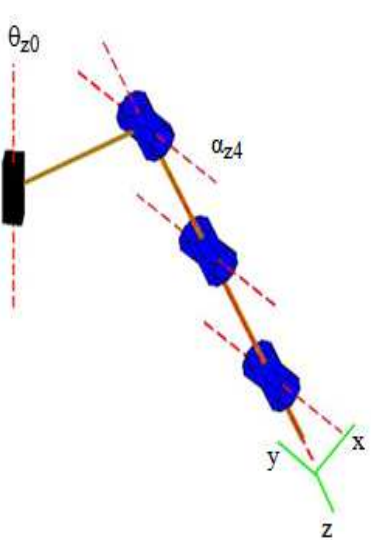

(b)
Fig. 5: Link kinematic of left arm in position 4

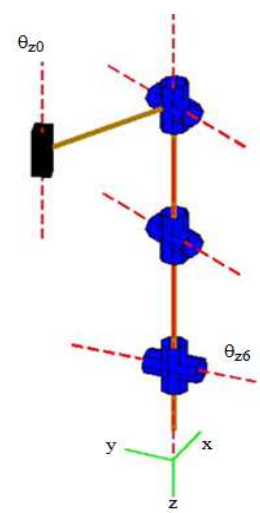

(a)

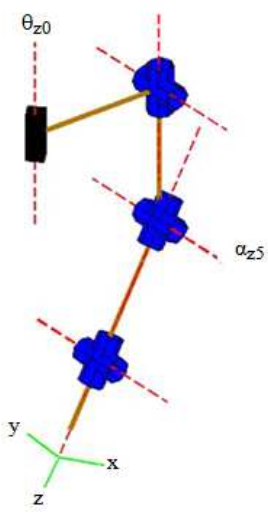

(b)
Fig. 6: Link kinematic of left arm in position 5
For this study, we study the kinematic of exoskeleton suit for increasing the performance of human arm. The simulation idea details for future study to construct the real exoskeleton suit. The structure of exoskeleton should be made from high quality material that gives high strength and low weight such as aluminum alloys. The exoskeleton should be designed to have more DOF. It will increase the complexity and flexible motion like human arm. The algorithm should be designed to control both speed and position of exoskeleton suit. In the addition, the motion of exoskeleton should be moved smoothly.

\section{CONCLUSION}

This study introduces the kinematic of exoskeleton suit for human arm.

The exoskeleton suit can be used to be instrument for anyone who needs to improve human's performance. It will increase the strength of human that can lift heavy load or help handicapped patients, who cannot use their arm. So, users will feel comfortable when wearing this instrument. Moreover, it can be applied in industry application to move or lift the load in the area, in where the vehicles or crane cannot use. The simulation for controlling the exoskeleton suit to follow the motion of human arm is programmed by MATLAB software.

\section{ACKNOWLEDGEMENT}

This research from measurement and Mobile robot Laboratory (M and M-LAB) was supported by Faculty of Engineering, Srinakharinwirot University. 


\section{REFERENCES}

Asfour, T. and R. Dillmann, 2003. Human-like motion of a humanoid robot arm based on a closed-form solution of the inverse kinematics problem. Proceeding of the International Conference on Intelligent Robots and Systems, Oct. 27-31, IEEE Xplore Press, USA., pp: 1407-1412. DOI: 10.1109/IROS.2003.1248841

Berns, K., H. Vogt, T. Asfour and R. Dillmann, 1998. Design and control architecture of an anthropomorphic robot arm. Proceeding of the International Conference on Advanced Mechatronics, Aug. 1998, IAIM, Okayama, Japan, pp: 1-6.

http://wwwiaim.ira.uka.de/users/asfour/publication s/ICAM-1998.pdf

McKerrow, P.J., 1991. Introduction to Robotics, Electronics Systems Engineering. 1st Edn., Addison-Wesley Publishing Company, USA., ISBN: 10: 0201182408, pp: 800.
Mittal, R.K. and I.J. Nagrath, 2003. Robotics and Control. 1st Edn., Tata McGraw-Hill Publishing Company Limited, New Delhi, ISBN: 10: 0070482934, pp: 489.

Nandhakumar, S., V. Selladurai and S. Sekar, 2009. Numerical investigation of an industrial robot arm control problem using haar wavelet series. Am. J. Eng. Applied Sci., 2: 584-589. http://www.scipub.org/fulltext/ajeas/ajeas24584589.pdf

Sen, M.D.L., A. Almansa and J.C. Soto, 2007. Adaptive control of robotic manipulators with improvement of the transient behavior through an intelligent supervision of the free-design parameters and the sampling period. Am. J. Applied Sci., 4: 346-353. http://www.scipub.org/fulltext/ajas/ajas46346-353.pdf 